\title{
РОЛЬ СОЦИАЛЬНЫХ ФАКТОРОВ РИСКА В РАЗВИТИИ ЯЗВЕННОЙ БОЛЕЗНИ В КУРСКОЙ ОБЛАСТИ
}

\author{
(C) Лазаренко В.А., Антонов А.Е.
}

\author{
Кафедра хирургических болезней факультета последипломного образования \\ Курского государственного медицинского университета, Курск \\ E-mail: drantonov@mail.ru
}

\begin{abstract}
Динамичное изменение социокультурной среды и экономических условий жизни в современном обществе делает необходимым проведение повторных исследований, посвященных анализу факторов риска развития язвенной болезни (ЯБ). В статье представлен анализ данных о факторах риска 176 пациентов, находившихся на стационарном лечении в больницах города Курска за период с 2002 по 2012 год по поводу ЯБ. Показано, что среди таких больных доля незанятого населения достигает 44,9\% $(\mathrm{m}=3,7)$, несмотря на то что 75,6\% пациентов находится в трудоспособном возрасте, и средний возраст составляет 48,1 года $(\mathrm{m}=1,23)$. Установлено, что наличие ЯБ существенно негативно сказывается на материальном положении пациентов, повышая со временем долю затрат на лечение $(\mathrm{z}=0,46, \mathrm{P}<0,01)$ при сопутствующем связанном с возрастом увеличением доли затрат на питание среди таких больных $(\mathrm{z}=0,11, \mathrm{P}<0,05)$. Представлено также влияние вредных привычек, профессиональных вредностей, стрессов на длительность и степень тяжести заболевания.
\end{abstract}

Ключевые слова: язвенная болезнь, факторы риска, профессиональные вредности, безработица, материальные затраты.

\section{THE ROLE OF SOCIAL RISK FACTORS IN PEPTIC ULCER DEVELOPMENT IN KURSK REGION Lazarenko V.A., Antonov A.E.}

Department of Surgical Diseases of Postgraduate Education Faculty of Kursk State Medical University, Kursk

The dynamic change in the socio-cultural environment and economic conditions of life in modern society makes it necessary to conduct the repeated research of peptic ulcer (PU) risk factors. The article presents the results of analyzing risk factors' data of 176 patients who were treated in hospitals of the city of Kursk during the period from 2002 till 2012. It was revealed that the percentage of unemployed among such patients reached $44.9 \%(\mathrm{~m}=3.7)$, though the most $(75.6 \%)$ of the patients were of employable age, and the average age amounted to 48.1 years $(\mathrm{m}=1.23)$. It was shown that the presence of PU has a significant negative impact on the patients' financial state, eventually increasing the treatment costs ratio $(\mathrm{z}=0.46, \mathrm{P}<0.01)$, with a concomitant age-related increase in expenditures on food $(\mathrm{z}=0.11, \mathrm{P}<0.05)$. The article also presents the effect of pernicious habits, professional hazards, and stresses on duration of the disease, and the degree of severity.

Keywords: peptic ulcer, risk factors, professional hazards, unemployment, living expenses.

Актуальность проблемы изучения причин развития язвенной болезни (ЯБ) определяется ее значительной распространенностью, достигающей $12 \%[4,5]$, риском развития угрожающих жизни осложнений, выявляемых у $15-21 \%$ таких пациентов [1]. Helicobacter pylori является одним из ведущих звеньев патогенеза. В то же время его отсутствие не исключает развитие ЯБ, а инфицирование приводит к ЯБ лишь у 10\% пациентов [2]. Таким образом, оценка социальных факторов риска развития этой патологии не утрачивает актуальность. Наряду с изложенным, динамичное изменение социокультурной среды и экономических условий жизни в современном обществе делает необходимым проведение повторных исследований, посвященных анализу факторов риска развития ЯБ, оказывающих наиболее значительное влияние в настоящее время [3]. Полученные данные необходимы для актуализации подходов к профилактике.
Целью нашего исследования стало изучение современных социальных факторов риска развития ЯБ в Курской области.

\section{МАТЕРИАЛЫ И МЕТОДЫ ИССЛЕДОВАНИЯ}

Для сбора данных о факторах риска нами были разработаны накопительная карта и опросник. Накопительная карта заполнялась исследователем на основании медицинской документации и включала сведения о поле пациента, дате поступления и степени тяжести при поступлении, диагнозе, продолжительности диагностического периода, проведенном обследовании, лечении, о наличии у больного инвалидности. Анкета заполнялась в ходе беседы с больным и содержала сведения истории настоящего заболевания и анамнеза жизни, в том числе данные о профессиональной деятельности, стрессах, вредных привычках, питании, проводимом лечении и семейном анамнезе. 
На начальном этапе было выполнено пробное анкетирование 19 пациентов, в ходе которого были выявлены и исправлены недостатки накопительной карты и анкеты. Материалы этих больных в исследовании не учитывались. На втором этапе произведен сбор данных о факторах риска 176 пациентов, находившихся на стационарном лечении в больницах города Курска за период с 2002 по 2012 год.

В целях проведения анализа полученных данных нами был разработан программный комплекс, включавший Визуальную среду оценки факторов риска (свидетельство о государственной регистрации программы для ЭВМ № 2013613667) и Визуальную среду параметрического корреляционого анализа факторов риска (свидетельство о государственной регистрации программы для ЭВМ № 2013613672). Применялись разноплановые методы статистической обработки данных, включающие оценку коэффициента корреляции с поправкой Фишера z, коэффициент взаимной сопряженности (полихорический показатель связи) К. Пирсона С, оценка их статистической значимости (Р) с применением критериев Стьюдента и $\chi^{2}$, регрессионный анализ.

\section{РЕЗУЛЬТАТЫ ИССЛЕДОВАНИЯ И ИХ ОБСУЖДЕНИЕ}

В анализируемой группе мужчин было достоверно $(\mathrm{P}<0,001)$ больше, чем женщин $66,5 \%$. Средний возраст составил 48,1 года $(\mathrm{m}=1,23)$, причем средний возраст мужчин и женщин значимо не отличался. Среди пациентов бо́ льшая $(\mathrm{P}<0,001)$ часть $-80,7 \%(\mathrm{~m}=3,0)$ не имели стойкой утраты трудоспособности. Доли инвалидов I, II и III групп составили $0,6(\mathrm{~m}=0,6)$, $8,5(\mathrm{~m}=2,1)$ и $10,2 \%(\mathrm{~m}=2,3)$ соответственно.

По состоянию при поступлении пациенты разделились следующим образом: $65,9 \%(\mathrm{~m}=3,6)$ поступили в удовлетворительном состоянии, $27,3 \%(\mathrm{~m}=3,4)-$ в состоянии средней степени тяжести, 5,7\% $(\mathrm{m}=1,7)-$ в тяжелом и $1,1 \%$ $(\mathrm{m}=0,8)-$ в крайне тяжелом состоянии. Средний балл по шкале ASA составил $0,7(\mathrm{~m}=0,04)$. Балл значимо не отличался у мужчин и женщин.

Значительной части - $17,3 \% \quad(\mathrm{~m}=2,9)$ больных потребовалось оказание оперативной помощи в ходе текущей госпитализации. Средняя продолжительность заболевания к моменту поступления составила 9,5 года $(\mathrm{m}=0,8)$ с учетом впервые выявленных случаев и 10,9 года $(\mathrm{m}=0,8)$ без таковых.

Таблица 1

Распределение пациентов с ЯБ по профессиональной деятельности

\begin{tabular}{|c|c|c|c|}
\hline Профессиональная деятельность & $\mathrm{p}(\mathrm{q}), \%$ & $\mathrm{~m}$ & Сравнение долей работающих и неработающих (t, P) \\
\hline Рабочий & 42,0 & 3,7 & \\
\hline Служащий & 9,7 & 2,2 & \\
\hline Безработный & 4,5 & 1,6 & \\
\hline Студент/Учащийся & 3,4 & 1,4 & \\
\hline Пенсионер/Неработающий инвалид & 33,0 & 3,5 & \\
\hline Домохозяйка/Домохозяин & 1,1 & 0,8 & \\
\hline Временно не работающий & 2,8 & 1,3 & \\
\hline Предприниматель/Бизнесмен & 3,4 & 1,4 & \\
\hline Итого работающие & 55,1 & 3,7 & \multirow{2}{*}{$\begin{array}{c}1,93, \\
>0,05\end{array}$} \\
\hline Итого неработающие и учащиеся & 44,9 & 3,7 & \\
\hline Итого работающие или учащиеся & 58,5 & 3,7 & \multirow{2}{*}{$\begin{array}{r}3,25, \\
<0,01\end{array}$} \\
\hline Итого неработающие, неучащиеся & 41,5 & 3,7 & \\
\hline
\end{tabular}

Таблица 2

Распределение больных по удовлетворенности профессией

\begin{tabular}{|c|c|c|c|c|c|c|c|c|c|}
\hline & \multicolumn{2}{|c|}{$\begin{array}{c}\text { Общая удовлетворенность } \\
\text { профессией }\end{array}$} & \multicolumn{2}{|c|}{$\begin{array}{c}\text { Материальная } \\
\text { удовлетворенность } \\
\text { профессией }\end{array}$} & \multicolumn{3}{|c|}{$\begin{array}{c}\text { Моральная } \\
\text { удовлетворенность } \\
\text { профессией }\end{array}$} \\
\cline { 2 - 11 } & $\begin{array}{c}\mathrm{p}(\mathrm{q}), \\
\%\end{array}$ & $\mathrm{~m}, \%$ & $\begin{array}{c}\mathrm{t}, \mathrm{P} \\
(\text { Да/Нет) }\end{array}$ & $\begin{array}{c}\mathrm{p}(\mathrm{q}), \\
\%\end{array}$ & $\mathrm{~m}, \%$ & $\begin{array}{c}\mathrm{t}, \mathrm{P} \\
(\text { Да/Нет) }\end{array}$ & $\begin{array}{c}\mathrm{p}(\mathrm{q}), \\
\%\end{array}$ & $\mathrm{~m}, \%$ & $\begin{array}{c}\mathrm{t}, \mathrm{P} \\
(\text { Да/Нет) }\end{array}$ \\
\hline Да & 66,7 & 3,9 & 6,43 & 42,0 & 4,1 & 0,73 & 56,7 & 4,2 & 3,93 \\
\hline Нет & 31,3 & 3,9 & $<0,001$ & 37,8 & 4,1 & Не дост. & 34,0 & 4,0 & $<0,001$ \\
\hline Сомневается & 2,0 & 1,2 & & 20,2 & 3,4 & & 9,3 & 2,4 & \\
\hline
\end{tabular}




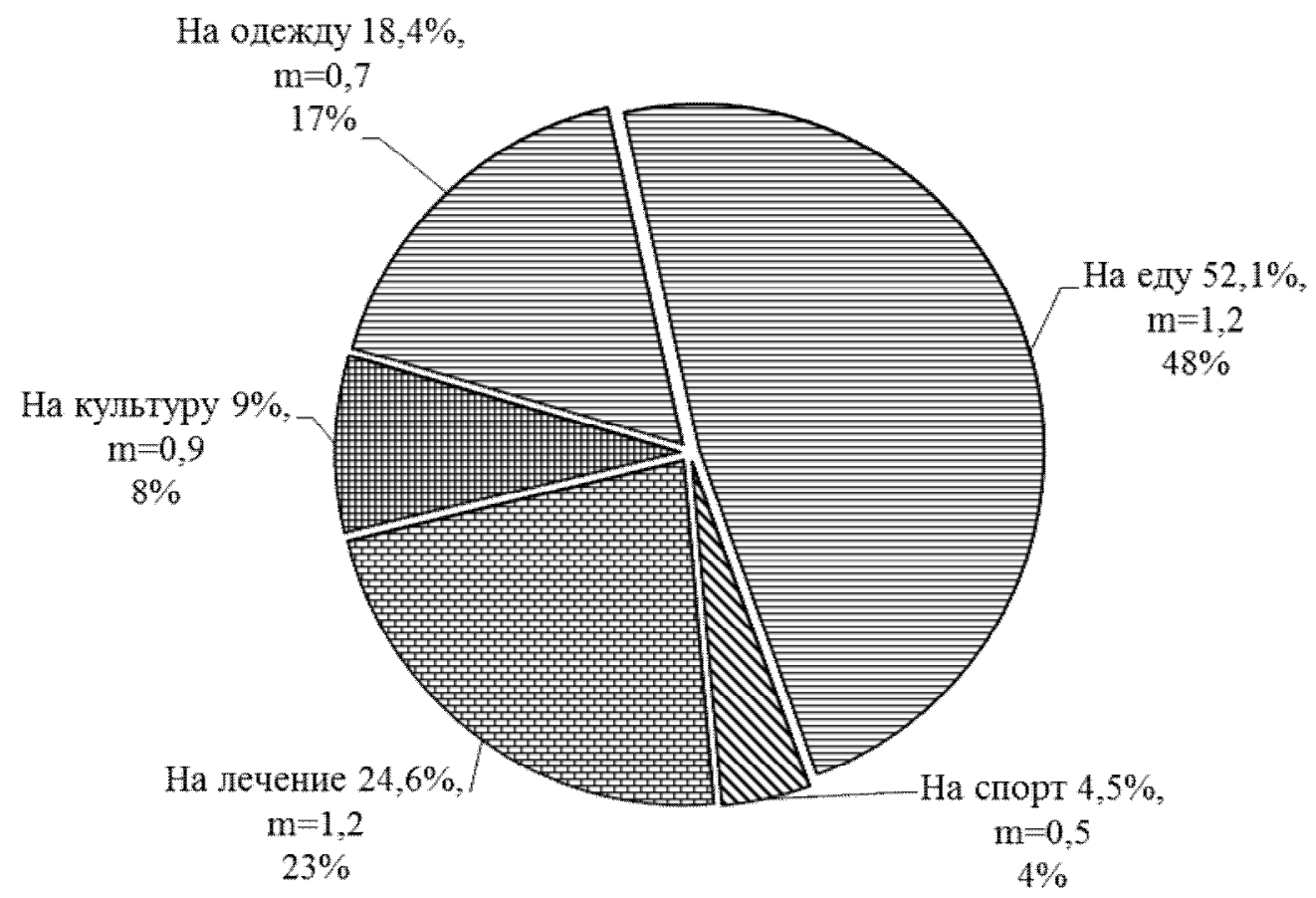

Рис. 1. Структура расходов пациентов.

Таблица 3

Корреляционные взаимосвязи некоторых количественных социальных факторов.

Коэффициент корреляции с поправкой Фишера z (верхняя часть) и его достоверность (нижняя часть)

\begin{tabular}{|c|c|c|c|c|c|c|c|c|}
\hline & Возраст & $\begin{array}{c}\text { Продолжительность } \\
\text { заболевания, } \\
\text { включая впервые } \\
\text { выявленные }\end{array}$ & $\begin{array}{l}\text { Затраты } \\
\text { на } \\
\text { питание }\end{array}$ & $\begin{array}{l}\text { Затраты } \\
\text { на } \\
\text { культуру }\end{array}$ & $\begin{array}{l}\text { Затраты } \\
\text { на } \\
\text { одежду }\end{array}$ & $\begin{array}{l}\text { Затраты } \\
\text { на } \\
\text { лечение }\end{array}$ & $\begin{array}{c}\text { Затраты } \\
\text { на } \\
\text { спорт }\end{array}$ & $\begin{array}{c}\text { Степень } \\
\text { тяжести при } \\
\text { поступлении } \\
\text { (балл ASA) }\end{array}$ \\
\hline Возраст & - & 0,27 & 0,11 & $-0,43$ & $-0,38$ & 0,46 & $-0,36$ & 0,13 \\
\hline $\begin{array}{l}\text { Продолжительность } \\
\text { заболевания, } \\
\text { включая впервые } \\
\text { выявленные }\end{array}$ & $\begin{array}{l}5,46 \\
\mathrm{P}<0,001\end{array}$ & - & $-0,02$ & $-0,14$ & $-0,28$ & 0,19 & $-0,19$ & $-0,10$ \\
\hline Затраты на питание & $\begin{array}{l}2,21 \\
P<0,05\end{array}$ & 0,43 & - & $-0,37$ & $-0,26$ & $-0,51$ & $-0,42$ & 0,08 \\
\hline Затраты на культуру & $\begin{array}{c}6,93 \\
P<0,001\end{array}$ & $\begin{array}{l}2,17 \\
\mathrm{P}<0,05\end{array}$ & $\begin{array}{l}6,05 \\
P<0,001\end{array}$ & - & 0,24 & $-0,42$ & 0,69 & 0,03 \\
\hline Затраты на одежду & $\begin{array}{c}7,36 \\
P<0,001\end{array}$ & $\begin{array}{c}4,91 \\
\mathrm{P}<0,001\end{array}$ & $\begin{array}{c}5,01 \\
\mathrm{P}<0,001\end{array}$ & $\begin{array}{c}3,95 \\
\mathrm{P}<0,001\end{array}$ & - & $-0,52$ & 0,26 & 0,04 \\
\hline Затраты на лечение & $\begin{array}{c}9,29 \\
\mathrm{P}<0,001\end{array}$ & $\begin{array}{c}3,47 \\
P<0,001\end{array}$ & $\begin{array}{l}10,23 \\
P<0,001\end{array}$ & $\begin{array}{c}6,65 \\
P<0,001\end{array}$ & $\begin{array}{l}9,65 \\
\mathrm{P}<0,001\end{array}$ & - & $-0,33$ & $-0,02$ \\
\hline Затраты на спорт & $\begin{array}{c}5,05 \\
P<0,001\end{array}$ & $\begin{array}{l}2,52 \\
P<0,05\end{array}$ & $\begin{array}{c}5,89 \\
P<0,001\end{array}$ & $\begin{array}{c}9,59 \\
\mathrm{P}<0,001\end{array}$ & $\begin{array}{c}3,67 \\
P<0,001\end{array}$ & $\begin{array}{c}4,58 \\
\mathrm{P}<0,001\end{array}$ & - & 0,19 \\
\hline $\begin{array}{l}\text { Степень тяжести при } \\
\text { поступлении (балл } \\
\text { ASA) }\end{array}$ & $\begin{array}{l}2,81 \\
P<0,01\end{array}$ & $\begin{array}{l}2,03 \\
P<0,05\end{array}$ & 1,65 & 0,41 & 0,79 & 0,36 & $\begin{array}{l}2,72 \\
P<0,01\end{array}$ & - \\
\hline
\end{tabular}

Почти каждый второй пациент с ЯБ на момент госпитализации нигде не работал и не учился (табл. 1), притом что большинство $(75,6 \%)$ пациентов находилось в трудоспособном возрасте.

В своей профессиональной деятельности $15,1 \%(\mathrm{~m}=2,7)$ больных работали с вредными веществами, 4,0\% $(\mathrm{m}=1,5)$ - с излучениями.
$15,3 \%(\mathrm{~m}=2,7)$ имели иные профессиональные вредности.

В целом большая часть больных была удовлетворена своей профессией (табл. 2).

При анализе сведений о расходах пациентов установлено, чтоб более $3 / 4$ своих доходов они тратили на питание и лечение (рис. 1). 
Таблица 4

Корреляционные взаимосвязи некоторых качественных социальных факторов. Коэффициент взаимной сопряженности (полихорический показатель связи) К. Пирсона С (верхняя часть)

и критерий $\chi 2$, связанный с ним (нижняя часть)

\begin{tabular}{|c|c|c|c|c|c|c|c|c|}
\hline & $\begin{array}{l}\text { Ин- } \\
\text { валид- } \\
\text { ность }\end{array}$ & $\begin{array}{c}\text { Консер- } \\
\text { вативное/ } \\
\text { Операти- } \\
\text { вное } \\
\text { лечение } \\
\end{array}$ & $\begin{array}{c}\text { Соци- } \\
\text { альное } \\
\text { положе } \\
\text { ние }\end{array}$ & $\begin{array}{l}\text { Профес- } \\
\text { сиональ- } \\
\text { ные } \\
\text { вреднос- } \\
\text { ти } \\
\end{array}$ & $\begin{array}{l}\text { Удовлетво- } \\
\text { ренность } \\
\text { профессией } \\
\text { (общая) }\end{array}$ & $\begin{array}{c}\text { Удовлетво- } \\
\text { ренность } \\
\text { профессией } \\
\text { (материаль- } \\
\text { ная) }\end{array}$ & $\begin{array}{c}\text { Удовлетво- } \\
\text { ренность } \\
\text { профессией } \\
\text { (моральная) }\end{array}$ & $\begin{array}{l}\text { Частота } \\
\text { обост- } \\
\text { рений }\end{array}$ \\
\hline Инвалидность & - & 0,06 & 0,43 & 0,18 & 0,09 & 0,12 & 0,13 & 0,18 \\
\hline $\begin{array}{l}\text { Консервативное/ } \\
\text { Оперативное } \\
\text { лечение }\end{array}$ & 1,55 & - & 0,20 & 0,06 & 0,10 & 0,11 & 0,12 & 0,24 \\
\hline $\begin{array}{l}\text { Социальное } \\
\text { положение }\end{array}$ & $\begin{array}{c}107,94 \\
\mathrm{P}<0,001\end{array}$ & $\begin{array}{l}19,78 \\
\mathrm{P}<0,025\end{array}$ & - & 0,22 & 0,27 & 0,30 & 0,28 & 0,25 \\
\hline $\begin{array}{l}\text { Профессиональ- } \\
\text { ные вредности }\end{array}$ & 15,98 & 1,72 & 25,22 & - & 0,18 & 0,13 & 0,16 & 0,18 \\
\hline $\begin{array}{l}\text { Удовлетворен- } \\
\text { ность профес- } \\
\text { сией (общая) }\end{array}$ & 3,45 & 4,40 & $\begin{array}{l}34,46 \\
P<0,005\end{array}$ & $\begin{array}{l}14,05 \\
\mathrm{P}<0,05\end{array}$ & - & 0,39 & & 0,18 \\
\hline \begin{tabular}{lr}
\multicolumn{2}{l}{ Удовлетворен- } \\
ность & профес- \\
сией & (матери- \\
альная) & \\
\end{tabular} & 6,39 & 5,29 & $\begin{array}{l}41,76 \\
P<0,001\end{array}$ & 6,88 & $\begin{array}{l}74,61 \\
\mathrm{P}<0,001\end{array}$ & - & 0,43 & 0,13 \\
\hline \begin{tabular}{lr}
\multicolumn{2}{l}{ Удовлетворен- } \\
ность & профес- \\
сией & (мораль- \\
ная) & \\
\end{tabular} & 7,03 & $\begin{array}{l}6,60 \\
\mathrm{P}<0,05\end{array}$ & $\begin{array}{l}36,72 \\
P<0,001\end{array}$ & 11,14 & & $\begin{array}{l}95,79 \\
\mathrm{P}<0,001\end{array}$ & - & 0,13 \\
\hline $\begin{array}{l}\text { Частота } \\
\text { обострений }\end{array}$ & 15,25 & $\begin{array}{l}28,53 \\
\mathrm{P}<0,001 \\
\end{array}$ & 32,61 & 15,09 & 14,02 & 7,05 & 6,78 & - \\
\hline
\end{tabular}

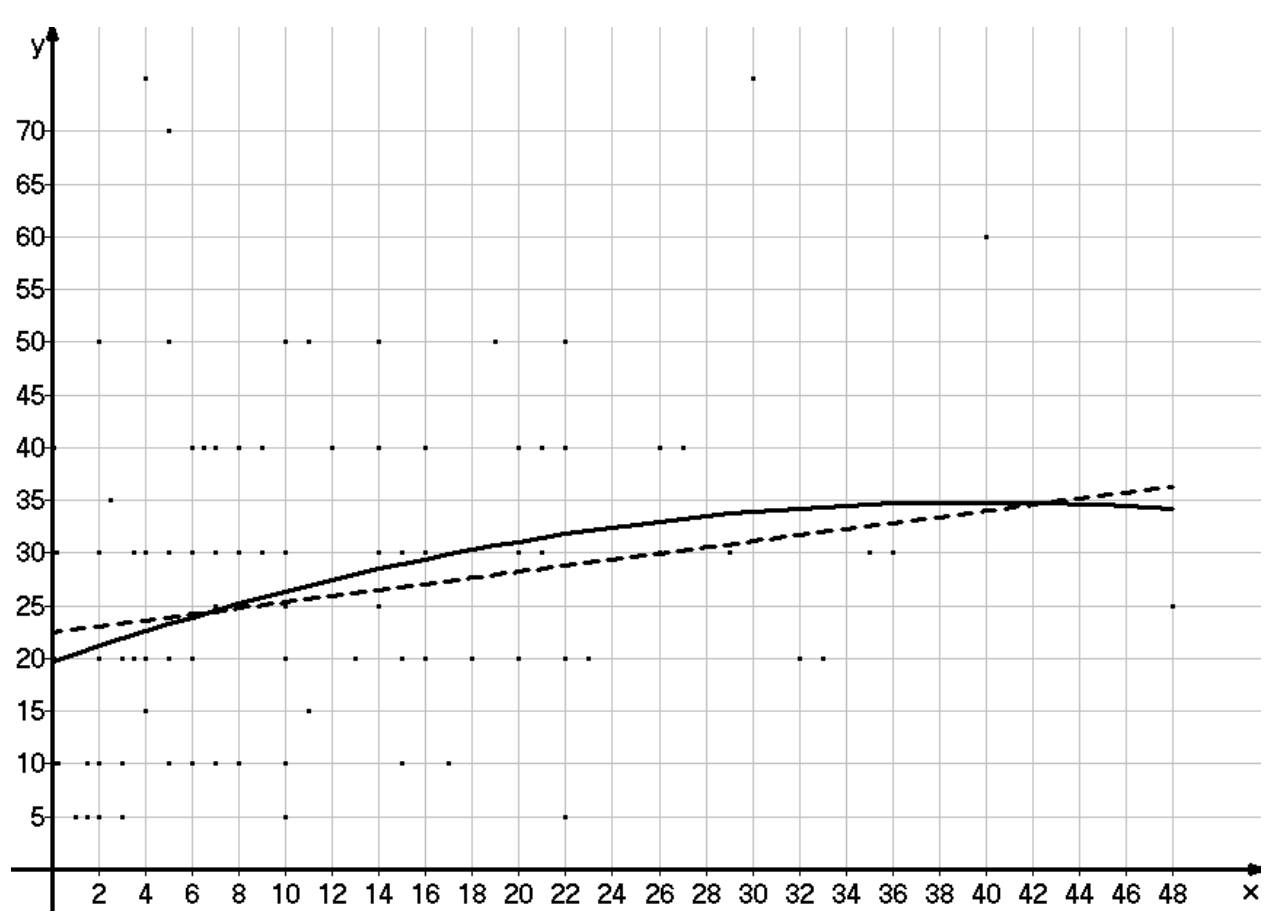

Рис. 2. Графики регрессий, отражающих связь продолжительности заболевания (по оси абсцисс влияющий признак, измеряемый в годах) и доли затрат на лечение (по оси ординат - зависимый признак, измеряемый в процентах) в анализируемой группе. Сплошная линия - график регрессии $\mathrm{y}=19,68+0,76 \mathrm{x}-0,01 \mathrm{x} 2$. Пунктирная линия - график множественной линейной регрессии $\mathrm{y}=7,77+0,29 \mathrm{x}$ $+0,29 \mathrm{z}$ (влияние признака возраст исключено). 
При исследовании корреляционных взаимосвязей между социальными факторами (табл. 3 и 4) выявлено достоверное влияние возраста на структуру материальных затрат в жизни больных. С ними связана также продолжительность заболевания. Степень тяжести при поступлении положительно коррелирует с возрастом $(\mathrm{P}<0,01) \quad$ и отрицательно - с продолжительностью заболевания $(\mathrm{P}<0,05)$. Это наблюдение может объясняться снижением доли больных с латентной ЯБ, манифестировавшей одним из осложнений. Выявлена взаимосвязь $(\mathrm{P}<0,025)$ социального положения и вида оказываемой медицинской помощи (оперативное или консервативное лечение).

Установлено значительное $(\mathrm{P}<0,001)$ влияние продолжительности заболевания на долю затрат на лечение (рис. 2). Причем выявлено, что темп роста затрат выше на начальных стадиях развития болезни. В дальнейшем отмечается стабилизация и снижение доли этого вида расходов. Данное наблюдение может быть обусловлено, в частности, общим снижением уровня доходов, на что косвенно указывает положительная корреляция расходов на питание и возраста больного.

Полученные данные позволяют сформулировать следующие выводы:

1. В клинико-статистическом исследовании установлено, что среди больных ЯБ, проходящих стационарное лечение, доля незанятого населения достигает 44,9\% $(\mathrm{m}=3,7)$, несмотря на то что большая часть $(75,6 \%)$ пациентов находится в трудоспособном возрасте, и средний возраст составляет 48,1 года $(\mathrm{m}=1,23)$.

2. Установлено, что наличие ЯБ существенно негативно сказывается на материальном положении пациентов, повышая со временем долю затрат на лечение $(\mathrm{z}=0,46, \mathrm{P}<0,01)$ при сопутствующем, связанным с возрастом увеличении доли затрат на питание среди таких больных ( $\mathrm{z}=0,11, \mathrm{P}<0,05)$.

\section{ЛИТЕРАТУРА}

1. Антонов А.Е., Лазаренко В.А., Новомлинец Ю.П. Хирургические аспекты условно-радикального лечения осложненной язвенной болезни // Вестник новых медицинских технологий. - 2006. - № 3. C. $150-152$.

2. Исаков В.A. Диагностика и лечение инфекции, вызванной Helicobacter pylori: IV Маастрихтское соглашение / Новые рекомендации по диагностике и лечению инфекции Н. Pylori. Best Clinical Practice. Русское издание - Маастрихт IV / Флоренция, 2012. - Вып. 2. - С. 4-23.

3. Лазаренко В.А., Суковатых Б.С., Антонов А.Е., Новомлинец Ю.П. Анализ факторов риска развития язвенной болезни в сравнении с другими заболеваниями гепатопанкреатодуоденальной зоны // Курский научно-практический вестник «Человек и его здоровье». - 2009. - № 1. - С. 95-100.

4. Helicobacter pylori in peptic ulcer disease [Электронный pecypc] // National Institutes of Health Consens Statement. - 1994. - Vol. 12, N 1. P. 1-23. - Режим доступа: https://consensus.nih.gov/1994/1994HelicobacterPylor iUlcer094html.htm, свободный (158.03.2016)

5. Tack J., Louis E., Persy V., Urbain D. Optimal use of proton pump inhibitors in primary care // Rev Med Liege. - 2014. - Vol. 69, N 3. - P. 139-145. 